
D:INsurg \Vol. 23, No. 4, Oct. - Dec., 2019\Nsurg-3.Doc
(A)
P. $264-269$
II

ORIGINAL ARTICLE

\title{
Intracranial Low Grade Glioma: a Clinical Study of 35 Cases in a Teaching Institute
}

\author{
SOHAIL AMIR, ${ }^{1}$ GOHAR ALI, ${ }^{2}$ KHALID MEHMOOD, ${ }^{2}$ NAEEM-UL-HAQ ${ }^{2}$ \\ ${ }^{1}$ Department of Neurosurgery, Hayatabad Medical Complex, Peshawar \\ ${ }^{2}$ Department of Neurosurgery, Mardan Medical Complex, Mardan - Pakistan \\ DOI: https://doi.org/10.36552/pjns.v23i4.381
}

\begin{abstract}
Objective: To determine the clinical manifestation and surgical outcome of patients with low grade Glioma.

Material and Methods: This descriptive (cross sectional) study was done at the Neurosurgery Department, Mardan Medical Complex Mardan. The study period was March 2017 to February 2018. Patient of any age and gender presented to outpatient department or referred from some other medical facility and diagnosed as low grade Glioma on clinical and radiological grounds and later confirmed by histopathology were included. Those with high grade Glioma or other tumors of the brain were excluded from the study. Patients' age, gender, clinical features, location of Glioma, post-operative outcome, and type of Glioma based on histopathology were recorded on predesigned Proforma. All patients were followed for one year.
\end{abstract}

Results: Out of 35 patients, 20 (57\%) were male and 15 (42\%) were female. 20 to 80 years was the age range and mean age was $46.36 \pm 17.11$ years. Frontal lobe was the most frequent area of location, followed by parietal $9(25 \%)$ and temporal 8 (22\%) lobe. Pre-operativeKarnofsky score was 90 in 16 (45\%), 80 in 8 (22\%), 70 in 6 $(17 \%)$ and 60 in $5(14 \%)$ of patients. Gross total resection was achieved in 13 (37\%), radical subtotal resection in 10 (28\%), subtotal resection in $10(28 \%)$ and biopsy taken in 02 (5\%) patients. histopathology revealed Astrocytoma in 15 (42\%), mixed Oligoastrocytoma in 12 (34\%) and Oligodendroglioma in 8 (22\%) number of patients. Post operatively surgical outcome was measured by improvement in symptomatology, Karnofsky score and seizure control. In our study Karnofsky performance score KPS improved in 11 (31.4\%) deteriorate in 4 (11.4\%), while in $20(57.1 \%)$ there is no change documented. Performance score improved more in patients with gross total resection.

Conclusion: Conscious level, Karnofsky Performance score, seizure control are important parameters for surgical outcome in patients with low grade Gliomas. Gross total resection of the tumor is a better option for good surgical outcome.

Keywords: Low grade Glioma, Karnofsky performance score, Seizure.

\section{INTRODUCTION}

The supporting glial cells of central nervous system make Gliomas which are neuroepithelial tumors. Gliomas present as, Oligodendroglioma,astrocytoma, mixed Oligoastrocytoma and glio-neuronal tumors. ${ }^{1,2}$ The World Health Organization (WHO) classifies Glioma from grade 1 through grade 4 i.e., low grade to high grade, depending on histological findings such as necrosis, atypical cytological pattern, mitotic activity and microvascular proliferation. ${ }^{3}$ The incidence of low grade Glioma (LGG) is 3.7 per 100,000 for male patients while 2.6 per 100,000 for female. ${ }^{4,5}$

Low grade Glioma (LGG) is commonly seen in middle age people with the third and fourth decade being highrisk and mostly located in motor cortex and insula. ${ }^{6,7} 80 \%$ of patients present with seizures. Cognitive function, autonomic function, sensory and motor function, social, emotional function all depend on location of tumor. Focal neurological deficit, cognitive changes, signs of raised intracranial pressure 
such as headache and papilledema are other common clinical features. ${ }^{8,9}$

LGGs are diagnosed by imaging, microscopic examination, and methods of molecular diagnosis. ${ }^{10}$ Magnetic Resonance imaging, MRI is a gold standard investigation and appears homogenous with low signal intensity of T-1 weighted and Fluid-Attenuated inversion recovery FLAIR sequences. Contrast enhancement is small if seen and is commonly associated with oligodendrogliomas. ${ }^{10-12}$

The treatment modalities of LGGs are conservative, surgery, radiation, chemotherapeutic approach, or a combination of all and management depends on site of tumor, histological pattern, and patient's features. Surgery is the major component of the whole management of gliomas. ${ }^{13-15}$ Increasing studies have favored surgical resection rather than conservative treatment to improve survival rates ${ }^{16}$.

The objective of the study was to determine the clinical profile and surgical outcome of intracranial low grade Glioma.

\section{MATERIAL AND METHODS}

\section{Study Design}

This descriptive (cross sectional) study was done at the Neurosurgery Unit at Mardan Medical Complex Mardan in the study period of March 2017 to February 2018. Approval was taken from the hospital ethical board and written informed consent was taken from all patients. Sample size was thirty five.

\section{Inclusion Criteria}

Patient of any age and gender presented to outpatient department or referred from some other medical facility and diagnosed as low grade Glioma on clinical and radiological grounds and later confirmed by histopathology were included.

\section{Exclusion Criteria}

Those with high grade Glioma or other tumors of the brain were excluded from the study.

\section{Data Collection}

Detailed history and clinical examination were done in all patients.Radiological investigation like CT Brain and MRI brain was done in all patients to diagnose low grade Glioma. On CT scan brain low grade Glioma appear as a diffuse area of low attenuation while on MRI it is homogenous with low signal intensity. Admissions were done through outpatient department and preoperative work up was done and prepared for surgery craniotomy and excision of Glioma was done. In some cases gross total excision while in other subtotal resection of the tumor was done. Biopsy was sent for histopathology. Postoperatively all patient were kept in Intensive care unit for 24 hours and then shifted to the ward.Patients were followed at 2 weeks, 1 month, 3 month, 6 month and 1 year.

\section{Data Analysis}

Karnofsky Performance Score (KPS) is a scoring system, evaluating the ability of cancer patients to execute everyday activities. The KPS scores range between 0 and 100. A higher number refers to better performance of the patient.Preoperative sign and symptoms, Karnofsky performance score, location of Glioma, type of Glioma on the basis of histopathology and post-operative outcome were written on predesigned Proforma. All the data was analyzed by SPSS version 20.0 and express in the form of tables.

\section{RESULTS}

\section{Gender Distribution}

Out of 35 patients, 20 (57\%) were male and 15 (42\%) were female.

\section{Age Distribution}

Age of the patients ranges from 20 years to 80 years with mean $46.36 \pm 17.11$ years.

\section{Clinical Features}

Symptoms of LGG were seizure $23(65.7 \%)$, focal deficit $21(60 \%)$, and headache in $17(48.5 \%)$ of Patients as shown in table 1. Note: Patient may present with one or combination of symptoms.

Frontal lobe was the commonest site of tumor, followed by parietal in $9(25 \%)$ and temporal $8(22 \%)$ lobe as shown in table 2. Tumor identified by MRI brain and later on confirmed by histopathology. All 35 (100\%) patient had gone through MRI Brain showing enhancement in $20(57 \%)$ cases. The pre-operative Karnofsky score was 90 in 16 (45\%), 80 in 8 (22\%), 70 in $6(17 \%)$ and 60 in $5(14 \%)$ of patients.

Gross total resection was performed in $13(37 \%)$, radical subtotal resection in 10 (28\%) subtotal 
Table 1: Presenting symptoms $(n=35)$.

\begin{tabular}{|l|c|c|}
\hline Presenting Symptoms & Patients & Percentage \\
\hline Seizure & 23 & $65.7 \%$ \\
\hline Headache & 17 & $48.5 \%$ \\
\hline Focal deficit & 21 & $60 \%$ \\
\hline Aphasia & 11 & $31.4 \%$ \\
\hline Visual defect & 8 & 22. \\
\hline Cognitive or behavior changes & 14 & 40 \\
\hline Coma & 5 & $14.2 \%$ \\
\hline
\end{tabular}

Table 2: Tumor location $(n=35)$.

\begin{tabular}{|l|c|c|}
\hline Tumor Location & Patients & Percentage \\
\hline Frontal lobe & 13 & $37.1 \%$ \\
\hline Parietal lobe & 9 & $25.7 \%$ \\
\hline Insula & 8 & $22.8 \%$ \\
\hline Occipital lobe & 3 & $8.5 \%$ \\
\hline Eloquent brain & 2 & $5.7 \%$ \\
\hline
\end{tabular}

Table 3: Tumor characteristic and outcome $(n=35)$.

\begin{tabular}{|l|c|c|}
\hline $\begin{array}{l}\text { Tumor Characteristic and } \\
\text { Outcome Variant }\end{array}$ & Patients & Percentage \\
\hline Histology & & \\
\hline Astrocytoma & 15 & $42.8 \%$ \\
\hline Mixed Oligoastrocytoma & 12 & $34.2 \%$ \\
\hline Oligodendroglioma & 8 & $22.8 \%$ \\
\hline Size & 18 & $51.4 \%$ \\
\hline Greater than 5cm & 10 & 28.55 \\
\hline less than 5 cm & 7 & $20 \%$ \\
\hline Unknown & 13 & $37.1 \%$ \\
\hline Extent of resection & 10 & $28.5 \%$ \\
\hline Gross total & 10 & $28.5 \%$ \\
\hline Radical subtotal & 02 & $5.7 \%$ \\
\hline Subtotal & & \\
\hline Biopsy only & 20 & $57.1 \%$ \\
\hline $\begin{array}{l}\text { Post-operative } \\
\text { radiotherapy }\end{array}$ & & \\
\hline Yes & & \\
\hline
\end{tabular}

\begin{tabular}{|l|c|c|}
\hline No & 15 & $42.8 \%$ \\
\hline $\begin{array}{l}\text { Postoperative } \\
\text { chemotherapy }\end{array}$ & 18 & $51.4 \%$ \\
\hline Yes & 17 & $48.5 \%$ \\
\hline No & 11 & $31.4 \%$ \\
\hline $\begin{array}{l}\text { Karnofsky performance } \\
\text { score (KPS) }\end{array}$ & 4 & $11.4 \%$ \\
\hline Improved & 20 & $57.1 \%$ \\
\hline Deteriorated & & \\
\hline unchanged & & \\
\hline
\end{tabular}

resection in $10(28 \%)$ and biopsy in $02(5 \%)$ number of patients. Histopathology revealed Astrocytoma in 15 (42\%), mixed Oligoastrocytoma in $12(34 \%)$ and Oligodendroglioma in $8(22 \%)$ number of patients.

\section{Outcome}

Post operatively surgical outcome was measured by improvement in symptomatology, Karnofsky score and seizure control. In our study, the Karnofsky performance score KPS improved in 11 (31.4\%) deteriorate in $4(11.4 \%)$, while in $20(57.1 \%)$ there is no change documented. 6 (17\%) Karnofsky Performance score improved in patients with gross total resection. In 3 (8.5\%) KPS improved with radical subtotal resection and $2(5 \%)$ with subtotal resection, however no change in KPS was noted in patients with biopsy only.

\section{DISCUSSION}

Low grade Glioma (LGGs) are grade 1 and II tumors per classification of the WHO grading system. ${ }^{17}$ Gliomas comprise $40 \%$ ofall primary CNS tumors. Astrocytoma represent $75 \%$ of all Gliomas, while mixed Oligoastrocytoma, Oligodendroglioma and other subtypes make the rest of $25 \% .^{18,19}$ In this study, the tumor was most commonly found in the $4^{\text {th }}$ decade of life and outcome of surgery is better in younger than aged patients which correlates with study done by Laws et al and Taylor et al. ${ }^{21,22}$ In our study, the preoperative Karnofsky score was 90 in 16 (45\%), 80 in 8 (22\%), 70 in $6(17 \%)$ and 60 in $5(14 \%)$ of patients. KPS improved in $11(31.4 \%)$ deteriorate in 4 (11.4\%), while in $20(57.1 \%)$ there is no change documented. Study done by Chang et al in 2008 in the University of 
California showed that $80 \%$ had KPS 90 and according to this study KPS was improved in $14 \%$ of patients which again coincide with our study. ${ }^{23}$

In our study frontal lobe was the commonest site of tumor, followed by parietal $9(25 \%)$ and temporal 8 (22\%) lobe. Study done by Duffau et $\mathrm{al}^{24}$ and Cavaliere et al ${ }^{25}$ showed that tumor more commonly located in a cerebral hemisphere involving the frontal lobe in majority of cases. ${ }^{24,25}$ In our study, tumor histopathology revealed Astrocytoma in 15 (42\%), mixed Oligoastrocytoma in $12(34 \%)$ and Oligodendroglioma in $8(22 \%)$ number of patients, similar study done by Van Veelen et al. ${ }^{20}$ in University Hospital Rotterdam showed astrocytoma WHO grade 2 in $80 \%$ patient.

In our study, the gross total resection was performed in 13 (37\%), radical subtotal resection (rSTR) in $10(28 \%)$ subtotal resection in $10(28 \%)$ and biopsy only in $02(5 \%)$ number of patients. Complete resection of the tumor was difficult because of its diffuse nature and difficult to differentiate from normal brain. Our results are comparable with that of Chang et al. ${ }^{26}$ having GTR in 33\% cases and STR in $67 \%$ cases. ${ }^{26}$ However, considering both retrospective and prospective analysis more surgeons favors maximal resection. Evrele ${ }^{27}$ at Osmangzai University Turkey had GTR in $45.3 \%$ and STR in 54\% patients. Post-operatively seizure controlled in our study was $55 \%$, which is comparable with some international studies where the figure ranges from 36 to $100 \% .{ }^{28}$

Radiotherapy has long been a standard of care for these Glioma after surgery. Randomized controlled trials have clearly demonstrated the benefits of adding RT. ${ }^{27,29}$ In our study, $57 \%$ of patient received radiotherapy while the rest were lost to follow-up.

There were several limitations in our study. Firstly, the sample size was small. Secondly, the patients should have been followed in order to know median survival of patients, Thirdly, the only Mardan Medical Complex was the study place, an extension of the study to the other local hospitals in this locality could have been given a better idea regarding the outcome of low grade Glioma.

\section{CONCLUSION}

Conscious level, Karnofsky Performance score, control of seizure are important parameters for surgical outcome in patients with low grade Gliomas. Gross total resection of the tumor isa better option for a good outcome.

\section{REFERENCES}

1. Louis DN, Ohgaki H, Weistler OD, et al. WHO classification of tumors of the central nervous system. Acta Neuropathol. 2007; 114: 97-109.

2. Wallner KE, Gonzales MF, Edwards MS, Wara WM, Sheline GE. Treatment result of juvenile pilocytic astrocytoma. J Neurosurg. 1998; 69: 171-6.

3. Youland RS, Brown PD, Giannni $\mathrm{C}$ et al. Adult low grade glioma: 19 year experience at a single institution. Am J Clin Oncol. 2013; 36: 612-9.

4. Ferlay J, Soerjomataram I, Dikshit R, Eser S, Mathers $\mathrm{C}$, Rebelo $\mathrm{M}$, et al. cancer incidence and mortality worldwide. Int J Cancer, 2015; 136: 359-86.

5. Parkin DM, Muir CS, Whelan SL, Gao YT, Ferlay J, Powell $\mathrm{J}$ et al. cancer incidence in 5 continents. Int Agency Res Cancer, 2002; 31 (6): 1033-9.

6. Pouratian N, Asthagiri A, Jagannathan J et al. Surgery insight: The role of surgery in the management of low grade glioma. Nat Clin Pract Neurol. 2007; 3: 628-39.

7. Pirzkall A, Nelson SJ, Mcknigt TR et al. Metabolic imaging of low grade gliomas with three-dimensional magnetic resonance spectroscopy. Int J Radiat Oncol Biol Phys. 2002; 53: 1254-64.

8. Ricard D, Idbaih A, Ducray $F$ et al. Primary brain tumors in adult. Lancet, 2012; 379: 1984-86.

9. Baehring JM, Bi WL, Bannykh S et al. Diffusion MRI in the early diagnosis of malignant glioma. J Neurooncol. 2007; 82: 221-5.

10. Fan GG, Deng QL, Wu ZH et al. Usefulness of diffusion-weighted MRI in patient with non-enhancing supratentorial gliomas: A valuable tool to predict tumor grading. Br J Neurooncol. 2006; 79: 652-8.

11. Andronesi OC, Kim GS, Grestmer E et al. Detection of 2-hydroxygluterate in IDH mtatedglioma present by in vivo spectral-editing and $2 \mathrm{D}$ correlation magnetic resonance spectroscopy. Sci Transl Med. 2012; 4: 1164.

12. Pamir MN, Ozduman K, Vildiz E et al. intraoperative magnetic resonance spectroscopy for identification of residual tumor during low grade glioma surgery: clinical article. J Neurosurg. 2013; 118: 1191-8.

13. Peraud A, Ansari H, Bise K et al. clinical outcome of supratentorial astrocytoma WHO grade II. Acta Neurochir (Wien), 1998; 140: 1213-22.

14. Englot DJ, Han SJ, Berger MS et al. Extent of surgical resection predicts seizure freedom in low grade temporal lobe brain tumors. J Neurosurgery, 2012; 70 : 921-8.

15. Sanai I, Berger MS. Glioma extent of resection and its impact on patient outcome. J Neurosurgery, 2008; 62: 753-64.

16. Shaw EG, Wang M, Coons SW et al. Randomize trial of radiation therapy plus procarbazine, lomustine and vincristine chemotherapy for supratentorial adult low grade glioma. J Clinoncol. 2012; 30: 3065-70. 
17. Louis DN, Ohgaki H, Wiestler OD, et al. The 2007 WHO classification of tumours of central nervous system. Acta Neuropathol. 2007; 114: 97-109.

18. Yeh SA, Lee TC, Chen HJ et al. Treatment outcomes and prognostic factors of patients with supratentorial low grade oligodendroglioma. Int J Radiat Oncol Biol Phys. 2002; 54: 1405-1409.

19. Claus EB, Horlacher A, Hsu L, Schwartz RB, Dello Lacono, et al. Survival rate in patients with low grade glioma after intraoperative magnetic resonance image guidance. Cancer, 2005; 103: 1227-33.

20. Van Veelen ML, Aveezat CJ, KrosJM,VanPutten W, Vecht C. Supratentorial low-grade astrocytoma: prognostic factors, in well deferntiation, and the issue of early versus late surgery. J Neurol Neurosurg Psychiatry, 1998; 64: 581-7.

21. Laws ER, Taylor WF, Clifton MB, Okazaki H. Neurosurgical management of low grade astrocytoma of the cerebral hemisphere J Neurosurg. 1984; 61: 66573.

22. Leighton C, Fischer B, Banuman G, Depiero S, Stitt L, Macdonald D, et al. Supratentorial low-grade glioma in adults: and analysis of prognostic factors and timing of radiation. J Clin Oncol. 1997; 15: 1294-301.

23. Kreth FW, Faist M, Rossner R, Volk B, Ostertag CB. Supratentorial world health organization grade 2 astrocytomas and oligoastrocytoma. A new pattern of prognostic factors. Cancer, 1997; 79: 370-9.

24. Duffau $\mathrm{H}$ and Capelle L. Preferntial brain locations of low-grade gliomas. Cancer,

25. Cavaliere R, Lopes MBS, Schiff D. Low-grade gliomas: and update on pathology and therapy. Lancet Neurol. 2005; 4: 760-70.

26. Chang EF, Smith JS, Chang SM, Lamboron KR, Prados $\mathrm{MD}$, Butowski $\mathrm{N}$ et al. Preoperative prognostic classification system for hemispheric low-grade glioma in adults. J Neurosurg. 2008; 109: 817-24.

27. Everli D. Efficacy of Prognostic factors on survival in patients with low grade glioma. Turkish Neurosurg. 2008; 18: 336-44.

28. Englot DJ, Berger MS, Barbaro NM, Dario J. Predictors of seizure freedom after resection of supratentorial lowgrade gliomas. J Neurosurg. 2011; 115: 240-4.

\section{Additional Information}

Disclosures: Authors report no conflict of interest.

Ethical Review Board Approval: The study was conformed to the ethicalreview board requirements.

Human Subjects: Consent was obtained by all patients/participants in this study.

Conflicts of Interest:

In compliance with the ICMJE uniform disclosure form, all authors declare the following:

Financial Relationships: All authors have declared that they have no financial relationships at present or within the previous three years with any organizations that might have an interest in the submitted work.

Other Relationships: All authors have declared that there are no other relationships or activities that could appear to have influenced the submitted work.

Address for Correspondence:

Dr. Sohail Amir

Department of Neurosurgery

Hayatabad Medical Complex, Peshawar

Email ID:dr.sohailamir@gmail.com 


\begin{tabular}{|c|c|c|c|}
\hline \multicolumn{4}{|c|}{ AUTHORSHIP AND CONTRIBUTION DECLARATION } \\
\hline Sr.\# & Author's Full Name & Intellectual/Contribution to Paper in Terms of: & \multirow{3}{*}{$\begin{array}{l}\text { Signature by the } \\
\text { author(s) }\end{array}$} \\
\hline 1. & $\begin{array}{l}\text { Sohail Amir } \\
\text { (Main/Principal Author). }\end{array}$ & $\begin{array}{l}\text { 1. Proposed topics and Basic Study Design, } \\
\text { methodology. }\end{array}$ & \\
\hline 2. & Gohar Ali & \multirow{3}{*}{$\begin{array}{l}\text { 2. Data collection and calculations } \\
\text { 3. Analysis of data and interpretation of results etc. }\end{array}$} & \\
\hline & & & \\
\hline 3. & $\begin{array}{l}\text { Khalid Mehmood } \\
\text { (3rd Author) }\end{array}$ & & \\
\hline 4. & $\begin{array}{l}\text { Naeem-ul-Haq } \\
\text { (4th Author) }\end{array}$ & 4. Literature review and manuscript writing & \\
\hline
\end{tabular}

Date of Submission: 06-10-2019

Date of Revision: 30-11-2019

Date of Online Publishing: 25-12-2019

Date of Print: 31-12-2019 